\title{
LAS PLANTAS USADAS EN LA CONSTRUCCIÓN Y EL ACONDICIONAMIENTO DE LAS VIVIENDAS Y TEMPLOS GUARANÍES EN MISIONES, ARGENTINA
}

\author{
HÉCTOR A. KELLER ${ }^{1}$
}

Summary: Keller, H. A. 2008. Plants used to build and to prepare Guarani houses and temples in Misiones, Argentina. Bonplandia 17(1): 65-81. ISSN: 0524-0476.

\begin{abstract}
A study about the plants used in Guarani communities of Misiones Province, Argentina to build houses and temples is presented. Some topics about the abandonment of the traditional norms and materials of construction are discussed.
\end{abstract}

Key words: Ethnobotany, plant resources, houses, opy

Resumen: Keller, H. A. 2008. Las plantas usadas en la construcción y el acondicionamiento de las viviendas y templos guaraníes en Misiones, Argentina. Bonplandia 17(1): 65-81. ISSN: 0524-0476.

Se presenta un estudio sobre las plantas empleadas en comunidades guaraníes de Misiones para erigir estructuras habitacionales y religiosas. Se discuten algunos puntos relativos al abandono de las pautas tradicionales de construcción.

Palabras clave: Etnobotánica, recursos vegetales, casas, opy

\section{Introducción}

En la Provincia de Misiones, Argentina, existen más de cincuenta comunidades guaraníes, casi todas ellas pertenecientes a la parcialidad Mbya; por su parte, los Ava Chiripa conforman unas pocas aldeas con menos de un centenar de integrantes. Muy pocos individuos de la parcialidad Pa'i tavytera integran ciertas aldeas mbya. Estas parcialidades del tronco lingüístico Tupí-Guaraní han mantenido hasta hoy en día muchas de sus pautas culturales tradicionales, incluyendo aspectos de su cosmovisión religiosa, métodos de subsistencia, agricultura de roza y quema, méto- dos de caza y pesca, recolección de recursos naturales, etc. Asimismo han adoptado estrategias de supervivencia y rasgos propios de la sociedad global envolvente, tales como empleos transitorios, comercialización de algunos productos, vestimenta, entre otros. El tipo de materiales usados para la construcción de viviendas, constituye un aspecto que se encuentra en plena etapa de transformación, de tal manera que es posible hallar comunidades que solamente utilizan recursos obtenidos de su entorno natural, comunidades que han adoptado elementos foráneos tales como chapas, clavos, madera aserrada, etc., así como también comunidades que han accedido a viviendas de mampostería a través de planes de

1 Facultad de Ciencias Forestales, UNaM, Eldorado, Misiones, Argentina. Correo electrónico: hkeller@facfor.unam.edu.ar 
desarrollo habitacional. En cambio, la construcción del templo llamado opy, por norma ancestral, requiere el uso exclusivo de ciertos materiales tradicionales, lo cual, probablemente ha contribuido a mantener hasta el presente el conocimiento y el uso de estos recursos que la selva ofrece.

El objetivo de esta contribución es dar a conocer los recursos vegetales usados por los guaraníes de Misiones para construir una estructura habitacional, como así también discutir las pautas tradicionales que los guaraníes tienen en cuenta al seleccionar dichos recursos.

\section{Materiales y Métodos}

Se ha realizado un detallado estudio etnobotánico durante los años 1998 a 2008, en diversas comunidades guaraníes de la Provincia de Misiones, Argentina. Este prolongado tiempo de estudio ha permitido abordar el trabajo de campo mediante varios métodos de la etnografía; desde encuestas estructuradas, caminatas con expertos locales, hasta la observación participante. Se ha participado en las diferentes etapas de la construcción de templos, viviendas y quinchos, desde la obtención de materia prima hasta el acabado final, ello ha permitido apreciar los detalles inherentes a cada una los tópicos descriptos en esta contribución.

Se han coleccionado ejemplares de las especies vegetales vinculadas al tema aquí tratado y las muestras originales se hallan depositadas en el herbario CTES del Instituto de Botánica del Nordeste, Corrientes, Argentina, con varios duplicados en otras instituciones. Un ejemplar de cada especie se detalla en el apéndice. Se han obtenido además algunos materiales etnográficos que se hallan depositados en CTES.

\section{Resultados}

En el apéndice se presenta un listado de 98 especies vegetales que se utilizan o se mencio- nan para la construcción y acondicionamiento de templos y viviendas de los guaraníes de Misiones, Argentina. Todas ellas son Angiospermas, 33 Monocotiledóneas y 65 Dicotiledóneas. En dicho listado se incluyen los nombres guaraníes, sus usos, partes usadas y material testigo.

La construcción de los templos religiosos (opy) prevé ciertas reglas culturales en cuanto a materiales usados y protocolos de diseño, por ello este tema es tratado separadamente luego del acápite relativo las estructuras de amparo y abrigo.

\section{Refugios y viviendas}

La primera vivienda, o mejor dicho el primer refugio, debió ser un árbol bajo el cual se cobijara el hombre, o bien entre sus ramas ante el temor de que su sueño fuera turbado por alguna fiera, más tarde se cobijó bajo el abrigo de peñas o cuevas más o menos profundas (Grimberg \& Svanström, 1982). La palmera Arecastrum romazoffianum es para los guaraníes de Misiones la especie vegetal con mayor valor de uso, debido en parte a la multiplicidad de aplicaciones que presenta (Keller, 2008). No obstante, su importancia trasciende el valor pragmático y adquiere relevancia simbólica en la vida espiritual y en el folklore de este pueblo. Algunas leyendas contadas por los ancianos mbya adjudican a esta especie nada menos que salvación de la raza guaraní durante el diluvio universal; cuentan que los sobrevivientes subsistieron encaramados en la copa de un ejemplar de esta palmera; sin duda se trata de un refugio mítico. Por otro lado, varias versiones afirman que su copa ha constituido un sitio de pernoctación seguro para los transeúntes de la selva, quienes sorprendidos por el anochecer han buscado el modo de mantenerse fuera del alcance de los predadores, otrora numerosos. La utilización de esta palmera como refugio consiste en armar una especie de gran cesta amarrando en torno al estípite varias de las hojas mediante una cuerda resistente y entretejiendo luego los segmentos foliares de las hojas seleccionadas. La particularidad de la palmera que ha permitido esta aplicación es la 
tenaz inserción de las vainas foliares al eje del estípite debido a la presencia de gruesos y resistentes cordones fibrosos, los cuales usualmente son también usados por los guaraníes para hacer cuerdas para arcos. La utilización de la copa de esta palmera como refugio se conoce con el nombre de "japu raity", que se traduce como "nido del ave japu" (Cacicus haemorrous), se trata de un ave que hace sus nidos también entretejiendo los segmentos de las hojas. En la figura 1A se representa una escena correspondiente a la leyenda transmitida por un anciano mbya, en la cual dos mujeres guaraníes al trasladarse de una comunidad a otra muy lejana, han debido pernoctar en la copa de una palmera. Bertoni (1941) ha mencionado para los Aché-guayakí del Paraguay este sistema de amparo sobre la misma palmera.

Extintos grupos indígenas que han ocupado esta región antes de la llegada de los guaraníes, han sabido aprovechar las cuevas naturales. La tradición Umbú, a la que pertenecían cazadores recolectores que habitaron el territorio que hoy constituye la provincia de Misiones, entre los 5950 y 2450 años antes del presente, han ocupado una gran caverna que hoy se conoce cómo la Gruta 3 de Mayo, en el departamento Libertador General San Martín, Misiones (Poujade, 1995). Sin embargo, los guaraníes son especialmente renuentes a cobijarse, e inclusive a aproximarse a cuevas naturales, pues consideran que están habitadas por espíritus malignos. A poca distancia de una aldea situada en la Reserva de Biosfera Yabotí hay una enorme cueva socavada en la roca (Fig. 1B), los guaraníes la conocen como ita oga (la casa de piedra), no obstante evitan en lo posible aproximarse a ella, temerosos de ser afectados por el espíritu ita ja (dueño de las rocas). Es probable que estas creencias hayan tenido su origen en la efectiva ocupación de estos sitios por etnias desconocidas para los guaraníes.

La permanencia en un sitio por varias noches exige la construcción de un refugio, Müller (1989) sugiere que el paraviento, un simple armazón de palos cubiertos con hojas de las Arecastrum romanzoffianum o Butia yatay (Arecaceae), ha sido una de las más primitivas vivienda de estos pueblos. Los guaraníes aconsejan un cerco rudimentario en torno a los campamentos instalados en interior de selva, utilizando ramas del arbolito Sorocea bonplandii (Moraceae) (Fig. 1C), al cual aseguran que el jaguar siente temor y evita aproximarse. Este criterio tiene su asidero también en la mitología guaraní; pues según cuenta una leyenda, el héroe solar transformó en esta planta a un palo que utilizaba para golpear al jaguar.

El pasaje a la vida sedentaria, entre otras cosas ha permitido a los pueblos mejorar los diseños de los refugios para hacerlos más durables y confortables. La literatura sobre los guaraníes menciona la edificación de inmensas viviendas comunales o cabañas abovedadas de cerca de $50 \mathrm{~m}$ de longitud (Metraux, 1948). Sin embargo, ya a principios del siglo pasado, en el Alto Paraná, este tipo de edificaciones sólo se hallaba presente entre los guaraníes de la parcialidad Pa'i tavytera del Paraguay, siendo más comunes entre las otras parcialidades las viviendas familiares, más pequeñas y a dos aguas (Müller, 1989). Este proceso de regresión a viviendas más pequeñas y rudimentarias probablemente se debió a la interrupción reiterada del sedentarismo, dada la necesidad de desplazarse continuamente a medida que la sociedad occidental fue ganando terreno. Actualmente sólo quedan vestigios de las viviendas comunales en algunas construcciones pertenecientes a líderes religiosos renombrados, estas son llamativamente grandes y con sus dos extremos redondeados (Fig. 1D). Lo más usual es que las viviendas de las familias guaraníes consten de dos construcciones pequeñas, un habitáculo para dormir (tapyi), con una puerta como única abertura y una estructura techada sin paredes, para cocinar y reunirse bajo la sombra (oka). Algunas familias no cuentan con este último espacio, en cuyo caso en verano suelen cocinar bajo la sombra de algún árbol en el patio, y en invierno en el interior de los tapyi.

Las habitaciones tapyi y los quinchos oka tienen la misma estructura o esqueleto que consiste en una armazón de dos aguas (Fig. $1 E)$. La construcción se inicia implantando en el suelo cuatro columnas, las centrales más altas se denominan akamby ete (Fig 1E-I) y las cuatro laterales, más bajas se denominan 

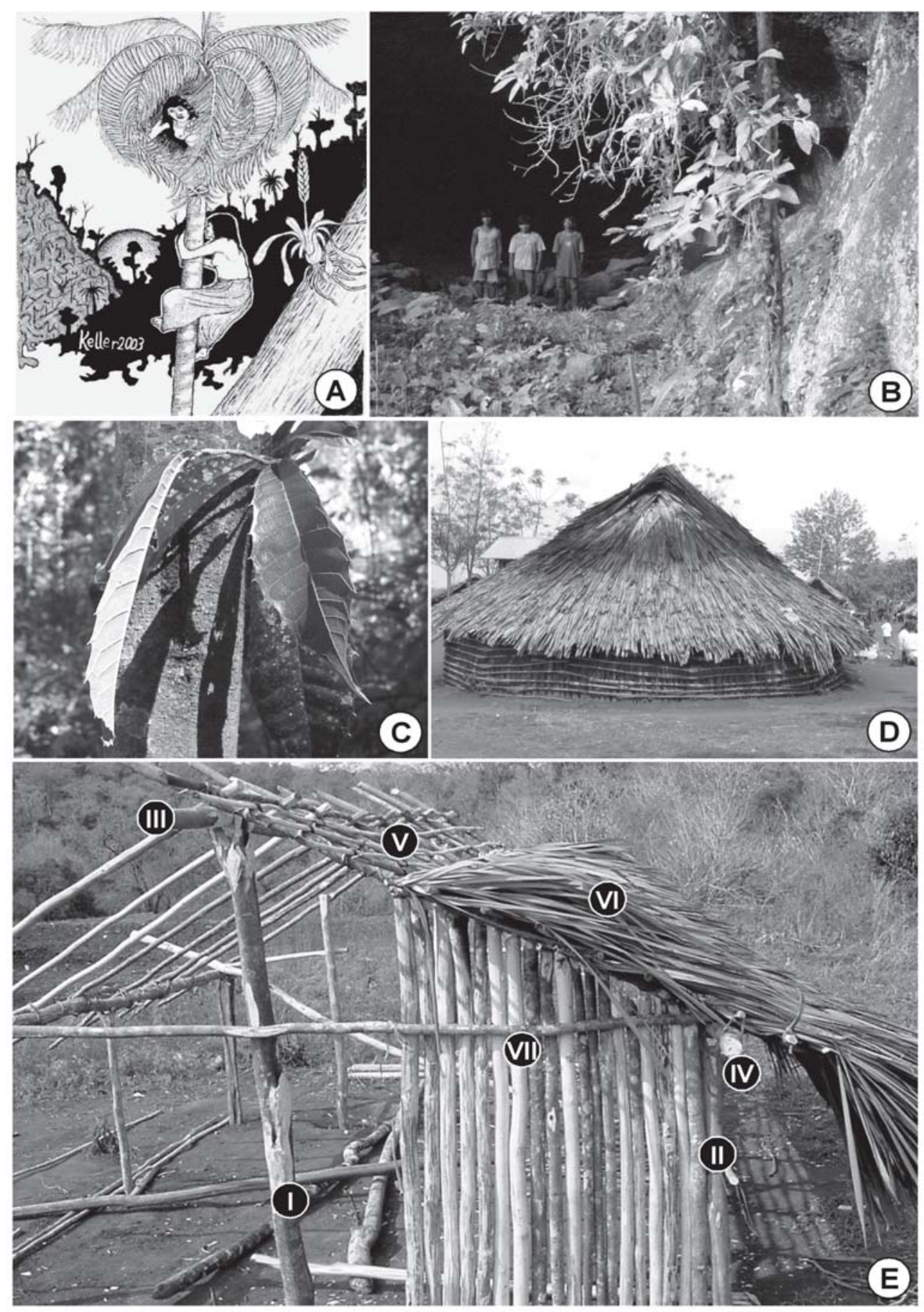

Fig. 1. A: representación alegórica del sistema de refugio en una palmera; B: caverna ita-oga en la Reserva de Biosfera Yabotí; C: tronco y hojas de Sorocea bonplandii; D: vivienda tradicional con los extremos redondeados; E: vivienda en construcción donde se detalla: un horcón central (I), un horcón lateral (II), la viga central (III), una viga lateral (IV), el bastidor del techo (V), el techo de hojas de Cordyline spectabilis (VI) y la pared de rollizos (VII). 
akamby miri (Fig. 1E-II). Estas columnas consisten en troncos de árboles con fuste recto y madera más o menos resistente al paso del tiempo. Las especies más mencionadas para este fin son Erythroxylum deciduum (Erythroxylaceae), Eugenia uniflora (Myrtaceae) y Cordia trichotoma (Boraginaceae). Sobre las columnas centrales se dispone una viga horizontal llamada akamby ete arygua (Fig. 1E-III), sobre las laterales se disponen vigas similares denominadas akamby miri arygua (Fig. 1E-IV). Estas vigas consisten en fustes delgados de especies arbóreas como Helietta apiculata (Rutaceae), o cañas de bambúes como Guadua angustifolia o Guadua trinii (Poaceae). Sobre estas vigas se disponen travesaños más delgados, paralelos a las vigas (iñaruka) y otros paralelas a la dirección de caída del techo (ijyta'i), conformando un enrejado denominado i'arygua (Fig. 1E-V) sobre el que se dispone el material usado para cubrir el techo. Este bastidor hecho con varas delgadas de especies leñosas o cañas delgadas de bambúseas como Merostachys claussenii (Poaceae), es sostenido a las vigas principales mediante una larga vara de sujeción denominada ijapyte arygua.

El material más ampliamente usado para cubrir los techos es también el tallo de Merostachys claussenii (Poaceae). Las poblaciones de esta bambúsea tienen ciclos de floración y muerte cada treinta años; y este ciclo es usualmente una medida de la edad de los ancianos (más de dos floraciones, mayores de sesenta años). Si bien ya se advirtieron los primeros indicios en el año 2003, la floración generalizada ocurrió en el año 2005. En el instante en que advirtieron el inicio de la floración, muchos guaraníes comenzaron a hacer planes para renovar los techos de las viviendas y templos, antes de la muerte de las cañas. Afirman que desde la germinación de las semillas y el inicio de la repoblación, deben pasar unos ocho años hasta que los tallos alcancen el diámetro adecuado para volver a utilizarlos para este fin. La floración y muerte de esta bambúsea, ocurrida durante una etapa del estudio etnobotánico, ha permitido registrar otros materiales alternativos para techar las viviendas; entre estos cabe mencionar las hojas de la palmera Arecastrum romanzoffianum, las ramas apicales de Cordyline spectabilis (Agavaceae) (Fig. 1EVI), tallos foliosos de gramíneas nativas como Andropogon bicornis, Schizachyrium microstachyum, o cultivadas como Oryza rufipogon (Fig. 2A), Pennisetum purpureum, etc. Para el distrito de los campos, al sur de Misiones, donde no es común hallar bambúseas, Martínez Crovetto registró en sus notas etnobotánicas inéditas, la utilización de diversas gramíneas para techar las viviendas guaraníes, entre estas Chloris polydactyla, Paspalum brunneum, etc.

La preferencia por la caña takuapi se debe a su comparativa resistencia, pues afirman que puede perdurar hasta ocho años, mientras que los otros materiales más foliáceos, solo duran uno o dos años. Un integrante de la parcialidad ava chiripa ha mencionado el uso pretérito de las anchas hojas de especies de Canna (Cannaceae), como material para techar las viviendas, pero no se pudo constatar la veracidad de esta afirmación.

Por lo general, tanto las dimensiones como la calidad de cada pieza de la construcción dependen de cuanto tiempo se estima o se desea prolongar la ocupación de la misma. La costumbre de encender fuego en el interior de estas estructuras, aumenta la durabilidad de todos los materiales utilizados (columnas, vigas, techos, ataduras, etc.), ya que los mismos se mantienen secos y en permanente contacto con el humo de la combustión.

Las ataduras o uniones de las piezas se suelen hacer mediante la liana Adenocalymna marginatum (Bignoniaceae) (Fig. 2B-I), las cuales son previamente retorcidas para conferirle mayor ductilidad; la torsión tramo a tramo permite separar los cordones xilemáticos y reducir la rigidez del tallo. También se usan las raíces aéreas de Philodendron bipinatifidum (Araceae), o su corteza, y si son ataduras de poca duración hasta pueden usarse cintas aplanadas obtenidas de la caña Merostachys clausenii (Poaceae) (Fig. 2B-II), hojas de Cordyline spectabilis (Agavaceae) y segmentos foliares de palmeras, como Arecastrum romazoffianum, Acrocomia totai, etc.

Las paredes de las viviendas suelen erigirse empleando una gran cantidad de palos im- 

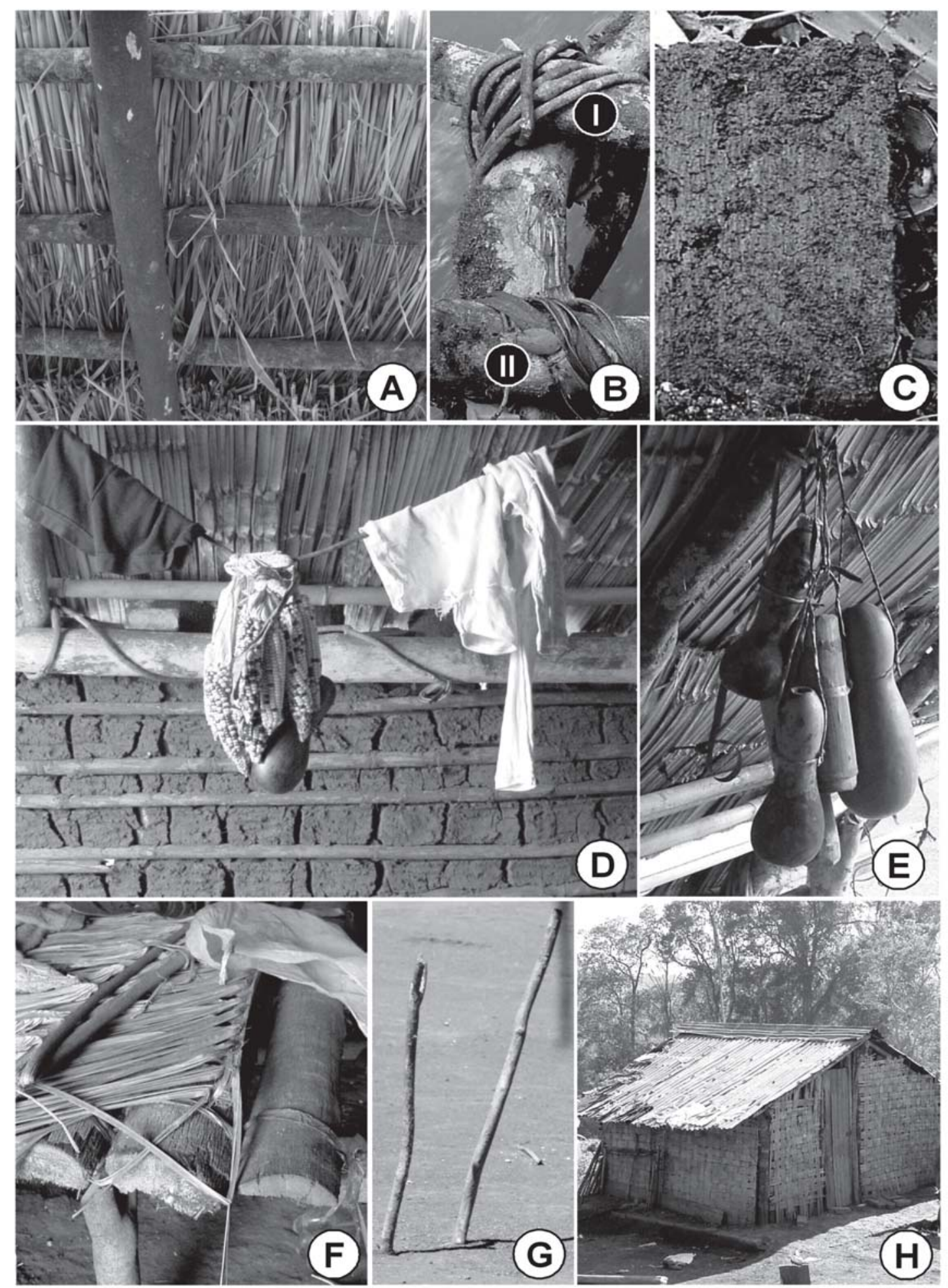

. 
plantados en el suelo uno junto a otros (Fig. $1 \mathrm{E}-\mathrm{VII})$, hasta cubrir toda la periferia, exceptuando el sitio donde se colocará la puerta. Estos palos consisten en rollizos de ciertos árboles, costaneros de estípites de palmera hendidos longitudinalmente, o bien costaneros de troncos de especie leñosas que se escinden fácilmente con hacha. Una de las especies preferidas para este fin es Styrax leprosus (Styracaceae), cuyo fuste es fácilmente hendible. Los rollizos tienen el defecto de dejar hendijas en los sitios donde el fuste no es completamente recto. Para sellar completamente estas hendijas se fijan transversalmente a las paredes y a cada 20 o $30 \mathrm{~cm}$, largas cañas de Merostachys clausenii (Poaceae) destinadas a contener una gruesa cubierta de barro. Este sellado permite retener el calor del día en las noches de invierno y las bajas temperaturas de la noche en los días verano. En una aldea abandonada hace más de noventa años se han hallado fragmentos del barro utilizado como sellante, en su superficie cóncava aún es posible ver la impronta que han dejado los ya desaparecidos estípites de la palmera Arecastrum romazoffianum (Fig. 2C). A veces el sellado con barro se efectúa sólo del lado exterior, pero lo más usual es que se recubra también la superficie interna de las paredes (Fig. 2D). Martínez Crovetto, en sus notas inéditas, menciona "chorizos de barro" mezclado con tallos de Bulbostylis juncoides (Cyperaceae), como un método para erigir paredes de viviendas guaraníes.

Quienes no desean invertir mucho tiempo y trabajo con la cubierta de barro, suelen tapar las hendijas con ramas de Cordyline spectabilis (Agavaceae) o fardos apretados de vástagos de Schizachyrium microstachium, Zea mays, y otras poáceas. Al material destinado a cubrir las hendijas se lo denomina ipa'u-mboty-a (hendijas-tapar-material).

La puerta suele labrarse con hacha y consisten en una o dos piezas de madera maciza. Es también usual ver puertas confeccionadas con tallos de Merostachys clausenii (Poaceae) entretejidos a modo de entramado de cestería; este método algunas veces se aplica también a la confección de paredes.

Tanto el interior como el exterior de la vivienda es acondicionado para hacerla más confortable. El mobiliario interior más usual consiste en repisas, confeccionadas con flejes de caña sobre las cuales se conservan provisiones y ropa. Una vara de bambú u otro material, que se extiende de pared a pared sobre el fogón y se sitúa aproximadamente a dos metros del nivel del suelo, sirve como percha para poner a secar semillas, ropas, hojas medicinales, conservar la carne, etc. Otras veces se emplea un tallo de Adenocalymna marginatum (Bignoniaceae), en el cual se cuelgan dichos elementos (Fig. 2D).

Las vigas y varas que conforman el esqueleto del techo se encuentran a baja altura, lo que permite incrustar allí objetos diversos tales como peines, huesos, limas de afilar, o bien colgar recipientes de bambú o de Lagenaria siceraria (Cucurbitaceae) conteniendo mieles, semillas secas, grasas, medicinas, etc. (Fig. 2E).

El fogón se sitúa a poca distancia de la puerta de acceso. Si no cuentan con sustentáculos de metal, algunas veces utilizan el leño ignífugo de Cabralea canjerana (Meliaceae) como soporte de ollas.

Las camas hechas con flejes de bambú o de estípites hendidos de palmera, generalmente se confeccionan ya antes de finalizar por completo la construcción de la vivienda, sobre los flejes se colocan hojas de palmera para conformar un cobertor acolchonado (Fig. 2F). Las hojas de la palmera pindo que se usan en estos acolchados, así como también en techos, paredes, y hasta en cestas denominadas yru'ague deben ser previamente acondicionadas. Para ello primeramente cortan y desechan la vaina y el pecíolo, luego toman la lámina y escinden el último segmento del ápice foliar a lo largo de su vena media, al llegar la hendidura a la base del segmento la fisura se prolonga fácilmente a lo largo de la nervadura de toda la hoja, obteniéndose dos hemilimbos en unos pocos segundos. Como los segmentos se disponen ocupando varios planos, la siguiente tarea es aplastar la lámina para situarlos en un solo plano. Cada uno de estos hemilimbos aplanados se utilizan como materia prima para los diversos fines antes mencionados.

Frente a las viviendas familiares es usual ver en los patios una serie de dos o más varas de cerca de un metro de altura, alineadamente 
implantadas en el suelo y separadas cerca de treinta centímetros entre sí (Fig. 2G). La función de estos puntales es servir como elemento de apoyo de niños pequeños que ejercitan los primeros intentos de ponerse de pie y dar los primeros pasos. Usualmente consisten en los resistentes tallos y ramas de especies leñosas tales cómo Actinostemon concolor (Euphorbiaceae), Parapiptadenia rigida (Fabaceae), etc.

En las comunidades más tradicionales los patios se mantienen siempre limpios, quemándose diariamente la basura acumulada. Está práctica, además de cumplir una función higienizante y estética es una medida destinada a mantener alejados a los insectos y también a ciertos espíritus que causan enfermedades. Atendiendo a estos últimos dos objetivos se produce abundante humo en los patios de las viviendas durante el atardecer, quemando la basura acumulada luego de barrer el área, e incorporando a los montículos del barrido, ramas de Holocalyx balansae (Fabaceae), de Petiveria alliacea (Phytolaccaceae) y de tabaco, a veces también la piel de ciertos animales como el chavape- o hurón menor (Galictis cuja furax). Uno de los espíritus que se trata de alejar es kerái ja, que torna irritables e iracundos a los niños. Además del efecto esterilizador de esta práctica, se mantiene muy aseado el entorno y se ahuyenta a insectos molestos tales como jejenes y mosquitos, que de por sí generan irritación y enfado en los niños. El hábito de amontonar y encender diariamente la basura acumulada en los patios de las viviendas es tan común en poblaciones urbanas de influencia guaranítica, que genera disputas frecuentes con vecinos y sectores ambientalistas.

Con fines ornamentales o de sombra es usual que se cultiven diversas especies en torno a las viviendas. Muchas de las especies cultivadas en el ámbito doméstico cumplen además otras funciones tales como provisión de frutos para el consumo o para atraer aves que se cazan, medicinas, ramas para escobas, etc. Han adoptado muchas especies con flores vistosas que son comúnmente cultivadas en áreas rurales, a todas ellas denominan simplemente ypoty (flor).

La incorporación de pautas de la sociedad global en la construcción de la vivienda manifiesta un paulatino avance, es muy común hallar casas mixtas en su composición, es decir diseños tradicionales con techos de cartón, o con coberturas de polietileno. En la figura $2 \mathrm{H}$, se observa una curiosa casa con base de cemento, paredes de bambú y techos de zinc; la construcción original consistía en una vivienda de madera asignada por un programa de desarrollo habitacional, la misma fue quemada accidentalmente, lo cual es común, ya que ellos introducen el fogón en el interior de las viviendas con fines de calefacción. Sobre sus cimientos y aprovechando las chapas residuales se la volvió a levantar, usando tiras de bambú entretejido para confeccionar las paredes. También es común que las viviendas sean incineradas intencionalmente, ya que con el tiempo se llenan de plagas y alimañas a las que se considera causantes de ciertas enfermedades.

Algunos integrantes de las comunidades que han vivido estacionalmente como peones asalariados en las chacras de agricultores suelen emularlos construyendo ranchos con tablas de madera aserrada. Por otro lado, los planes de vivienda digna desarrollados por diversos programas de asistencia social han introducido algunos diseños de viviendas estables de maderas o mampostería en muchas de las aldeas cuya accesibilidad lo permite.

\section{Templos}

La palabra opygua, con la cual se reconoce al líder espiritual de la comunidad, puede traducirse como "el que habita en el templo", ya que esta edificación aparte de un lugar sagrado, es entre los Mbya también la vivienda del religioso y de su familia. En cambio los opygua que pertenecen a la parcialidad Ava Chiripa ubican su vivienda particular en proximidades al templo, reservando este para eventos religiosos sistemáticos, tales como ceremonias, festividades, etc. o bien eventos ocasionales, tales cómo curaciones o la búsqueda de intervención divina para tratar algún inconveniente.

A diferencia de las viviendas particulares, que admiten muchas variantes en cuanto a 
pautas de edificación y materiales utilizados, el templo u opy constituye una estructura sujeta a ciertas restricciones. En primer lugar, obedeciendo a un criterio religioso, su eje más largo debe tener orientación oeste-este y su única abertura, la puerta de acceso, debe apuntar hacia el poniente, dirección en la cual se halla la morada del dios Tupã. El fondo del templo cuenta con mesadas o repisas, donde se depositan los animales cazados y desollados en agradecimiento al dios Karai, cuya morada se encuentra hacia el este.

Respecto a los materiales, invariablemente las paredes se hacen con costaneros de estípites de la palmera Arecastrum romanzoffianum, recubiertos con una capa de barro que se sostiene con cañas de Merostachys clausenii (Poaceae). Para fijar las piezas no se deben utilizar clavos, alambres u otros elementos foráneos al entono natural. Los techos se confeccionan con cañas Merostachys clausenii (Poaceae), estas son previamente aplastadas en el sitio de la recolección, utilizándose para ello mazas de madera pesada (Fig. 3A); las cañas aplastadas son dispuestas en gruesas capas sobre las viviendas (Fig. 3B). Muy raramente se emplean como material para techar los templos las delgadas ramas foliosas de este bambú en vez de sus tallos aplastados (Fig. 3C). La desaparición temporaria de las poblaciones de esta bambúsea causa preocupación entre los opygua. En una aldea mbya, el religioso decidió consultar a las deidades durante su trance religioso acerca de cuál sería el material propicio para remplazar al estropeado techo de takuapi que cubre su templo; estos sólo admitieron un posible reemplazo provisorio, las láminas que se descartan en una industria del compensado de la madera, situada a no mucha distancia de la aldea. De manera que el uso de elementos foráneos algunas veces trasciende la vida cotidiana y se introduce inclusive en el plano espiritual.

Las columnas y vigas del templo se hacen preferentemente con troncos de Cedrela fissilis (Meliaceae) (Fig. 3D), pues afirman que el intenso aroma de esta madera es el medio por el cual desciende el mensaje divino. Por este motivo también suelen diseñar el mobiliario del templo (sillas, bancos, bateas de agua, etc.) con el leño de este árbol. Los asientos zoomórficos tradicionales (Fig. 3E) que forman parte del mobiliario de los templos, en algunas comunidades han evolucionado transformándose en artesanías comerciales que se venden a un precio elevado (Fig. 3F).

Entre los mbya la finalización de un templo involucra una ceremonia de ocupación, en la cual mientras los jóvenes interpretan melodías tradicionales en el patio, el líder religioso y su esposa entran al templo fumando tabaco y informando a los dioses en voz alta su inminente apropiación del sitio.

La cosmogonía guaraní rebosa de admoniciones catastróficas, los líderes religiosos anuncian el advenimiento de holocaustos tales como fuertes vientos, diluvios, incendios y eclipses permanentes asociados a la aparición de entidades monstruosas. Afirman que solo puede resistir el embate de estos cataclismos un templo erigido con los materiales normalizados y conteniendo individuos que ostentan gran fervor religioso. Un opygua que reside en el Parque Provincial Esmeralda, erigió un cerco perimetral de troncos de Cedrela fissilis (Meliaceae) y Cordia trichotoma (Boraginaceae) en torno a su templo (Fig. 3G). Según el, es la única manera de hacer frente a los fuertes vientos y al embate de entidades monstruosas que se desatarán en breve.

\section{Discusión}

La visión guaranítica del futuro con cataclismos periódicos que exterminan la vida sobre la tierra, ha llevado a Nimuendajú (1914) a sugerir que los integrantes de esta etnia ya no creen en ningún porvenir. Sin embargo, estas creencias apocalípticas están más arraigadas en una esperanza optimista de renovación, que en una actitud de desesperanza y pesimismo. Los mitos hablan de la creación de un mundo nuevo y lozano, que remplaza todo lo viejo, enfermo y viciado. Esta misma actitud positiva hacia las instancias de renovación parece inundar cada una de las actitudes de los guaraníes. La constante búsqueda de la tierra sin males, el abandono de un sitio de 


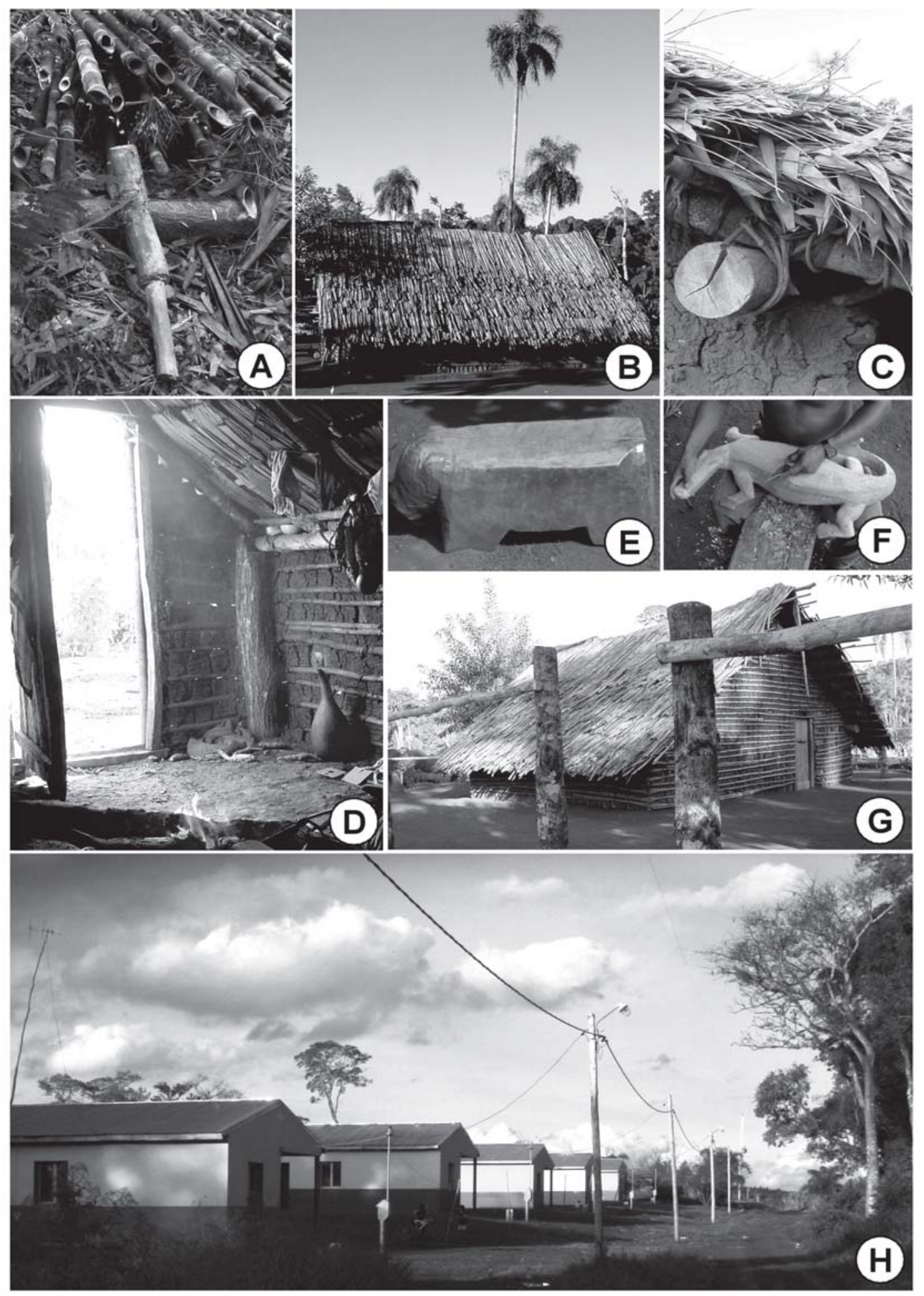

Fig. 3: A: cañas que serán aplastadas para techos; B: templo con techo de cañas; C: templo con techo de ramas foliosas de bambú; D: interior de templo en cuya esquina se aprecia un rollizo de Cedrela fissilis usado como horcón; F: asiento zoomórfico; G: artesanía comercial derivada de los asientos zoomórficos; H: cerco de protección de un templo; I: viviendas de mampostería agrupadas. 
asentamiento en busca de otro con mejores condiciones, el abandono de viejos terrenos de cultivos infestados con malezas agresivas por la apertura de nuevas parcelas para la siembra; la destrucción de una vieja morada para erigir una nuevo hogar, etc.

Las construcciones de los guaraníes (templos, viviendas, quinchos, espacios de cocina) son modestas y efímeras, se renuevan en períodos que van desde los dos a los ocho años. Usualmente al cumplir su ciclo son incineradas sin dejar rastros y la nueva construcción se realiza con materiales a estrenar. La renovación de la vivienda conlleva un saneamiento del entorno, eliminándose plagas y enfermedades albergadas en el suelo y entre las hendijas de la construcción vieja (ratas, pulgas, vinchucas, parásitos intestinales, etc.), también implica un cambio de paisaje cotidiano y una renovación en la vida de sus moradores, refrescando su estado de ánimo y cargándolos de optimismo. Sin embargo, esta dinámica habitacional es vista como un signo de indigencia por entidades de beneficencia, quienes establecen planes de "vivienda digna” edificando en las aldeas casas de mampostería o madera dura con bases cimentadas, las cuales desde su inicio constituyen un elemento que contamina el paisaje comunitario, y en corto tiempo se deterioran y se infectan con plagas y enfermedades que acarrean las mascotas o sus propios moradores. La durabilidad de sus materiales dificulta su eliminación del seno comunitario, imposibilitando la dinámica de renovación antes descrita. En muchas comunidades es usual ver el resurgimiento de chozas tradicionales al lado de las casas de mampostería.

Además de la perdurabilidad de las viviendas modernas, hay otros factores que tienden a desequilibrar las pautas tradicionales de ocupación del espacio. Los planes de vivienda, consisten en algunos casos en la edificación de varias casas situadas una al lado de otra (Fig. 3H). Esta disposición no es concordante con la de una comunidad guaraní típica, donde las viviendas familiares se hallan separadas por lotes de cultivo y fragmentos de selva. Estos, como muchos otros programas de desarrollo, que desde el desconocimiento del terreno se planifican sin previa consulta y contrariando pautas culturales, van socavando la etnoestima de culturas milenarias hasta el punto de que estas se asemejan y lo que es peor, se sienten identificadas con "villas miseria” u otro grupo marginal de la sociedad global. Dichos programas deberían contemplar la dinámica tradicional de ocupación de una vivienda, respetando la autodeterminación de cada familia.

\section{Agradecimientos}

A los integrantes de las comunidades guaraníes visitadas. Al Ing. Antonio Krapovickas por poner a mi disposición las notas de campo inéditas de Martínez Crovetto. Al Dr. Ernesto Maeder por la bibliografía proporcionada.

\section{Bibliografía}

BERTONI, M. S. 1941. Los guayakíes, caracteres antropológicos, razas etnológicas y reseña cultural. Rev. Soc. Cient. Paraguay 5(2):1-62.

GRIMBERG, C. \& R. SVANSTRÖM. 1982. Historia Universal I, al alba de la civilización. Ed. Daimon, Buenos Aires. 26 pp.

KELLER, H.A. 2008. Etnobotánica de comunidades guaraníes de Misiones, Argentina. Valoración de la vegetación como fuente de recursos. Tesis de doctorado en Recursos Naturales, Facultad de Ciencias Agrarias, Universidad Nacional del Nordeste. 282 pp.

METRAUX, A. 1948. The Guaraní. In Handbook of South American Indians, III. Washington.

MÜLLER, F. 1989. Etnografía de los Guaraní del Alto Paraná. Ed. Socieatis Verbi Divini, Rosario. 132 pp.

NIMUENDAJU (UNKEL), C. 1914. Die Sagen von der Erschaffung und Vernichtung der Welt als Grundlagen der Religion der Apapocúva-Guaran1'. Zeitschrift für Ethnologie. XLVI.

POUJADE, R.A. 1995. Mapa arqueológico de la provincia de Misiones (Cartilla explicativa). Artes gráficas Zamphirópolos, Asunción. p. 7-8.

Original recibido el 9 de junio de 2008; aceptado el 27 de junio de 2008. 
Apéndice. Lista de especies vinculadas a la construcción y acondicionamiento de viviendas y templos guaraníes, se detalla el nombre guaraní, el uso, la parte usada y un ejemplar testigo. Código de coleccionistas: C: Correa et al.; K: Keller o Keller et al.; MC: Martínez Crovetto; T: Tressens et al. Departamentos: C: Candelaria; E: Eldorado; G: Guaraní; I: Iguazú,L: Libertador General San Martín; M: Montecarlo; S: San Pedro.

\begin{tabular}{|c|c|c|c|c|}
\hline Especie & $\begin{array}{l}\text { Nombre } \\
\text { guaraní }\end{array}$ & Uso & Parte usada & Testigo \\
\hline \multicolumn{5}{|l|}{ DICOTYLEDONEAE } \\
\hline \multicolumn{5}{|l|}{ Anacardiaceae } \\
\hline Schinus terebenthifolia Raddi & $\begin{array}{l}\text { ryguaja } \\
\text { rembi'u }\end{array}$ & Cultivado para sombra en patios & Plantas & K 2954 (L) \\
\hline \multicolumn{5}{|l|}{ Asclepiadaceae } \\
\hline \multicolumn{4}{|l|}{ Apocynaceae } & K 661 (E) \\
\hline $\begin{array}{l}\text { Catharanthus roseus (L.) G. } \\
\text { Don. }\end{array}$ & ypoty & Cultivado como ornamental en patios & Plantas & K 1335 (S) \\
\hline \multicolumn{5}{|l|}{ Aquifoliaceae } \\
\hline Ilex paraguariensis A.St.-Hil. & ka'a & Cultivado como sombra en los patios & Plantas & K $1439(\mathrm{E})$ \\
\hline \multicolumn{5}{|l|}{ Asteraceae } \\
\hline Aspilia pascalioides Griseb. & ypoty & Cultivado como ornamental en patios & Plantas & K 1337 (S) \\
\hline $\begin{array}{l}\text { Baccharis dracunculifolia } \\
\text { DC. }\end{array}$ & ñerumi & Cultivado para sombra en patios, escobas & Plantas & K $1598(G)$ \\
\hline Zinnia peruviana (L.) L. & ypoty & Cultivado como ornamental en patios & Plantas & K 2846 (S) \\
\hline \multicolumn{5}{|l|}{ Bignoniaceae } \\
\hline $\begin{array}{l}\text { Adenocalymna marginatum } \\
\text { (Cham.) DC. }\end{array}$ & ychypo ũ & Ataduras de construcción, tendedero de ropa & Tallos & K 3467 (S) \\
\hline $\begin{array}{l}\text { Mansoa difficilis (Cham.) } \\
\text { Bureau \& K. Schum. }\end{array}$ & ychypo ũ & Ataduras de construcción & Tallos & T $4609(\mathrm{G})$ \\
\hline $\begin{array}{l}\text { Pyrostegia venusta (Ker } \\
\text { Gawl.) Miers }\end{array}$ & ychypo ete & Ataduras de construcción & Tallos & K 1359 (S) \\
\hline $\begin{array}{l}\text { Tabebuia heptaphylla (Vell.) } \\
\text { Toledo }\end{array}$ & tajy pytã & Horcones centrales y laterales para viviendas & Troncos & K $2210(G)$ \\
\hline \multicolumn{5}{|l|}{ Bombacaceae } \\
\hline $\begin{array}{l}\text { Ceiba speciosa (A.St.-Hil., } \\
\text { Juss. \& Cambess.) Ravenna }\end{array}$ & yvi & Soga para hamacas & $\begin{array}{l}\text { Fibras } \\
\text { liberianas }\end{array}$ & T $5632(\mathrm{G})$ \\
\hline \multicolumn{5}{|l|}{ Boraginaceae } \\
\hline Cordia ecalyculata Vell. & aruã moã & Cultivado como ornamental en patios & Plantas & K $1667(E)$ \\
\hline $\begin{array}{l}\text { Cordia trichotoma (Vell.) } \\
\text { Arrab. }\end{array}$ & apeteryvi & $\begin{array}{l}\text { Cercos para templos. Horcones centrales y } \\
\text { laterales para viviendas y templos, vigas para } \\
\text { viviendas y templos }\end{array}$ & Troncos & K $1666(E)$ \\
\hline Patagonula americana L. & guajayvi & Horcones centrales y laterales para viviendas & $\begin{array}{l}\text { Troncos, } \\
\text { ramas }\end{array}$ & T $4744(G)$ \\
\hline \multicolumn{5}{|l|}{ Cactaceae } \\
\hline Cereus stenogonus K. Schum. & $\begin{array}{l}\text { jakare } \\
\text { ruguái }\end{array}$ & Cultivado como ornamental en patios & Plantas & K $3020(G)$ \\
\hline Opuntia arechavalatae Speg. & tuna & Cultivado como ornamental en patios & Plantas & K $2003(G)$ \\
\hline
\end{tabular}


H. A. Keller, Las plantas usadas por los guaraníes en Misiones

\begin{tabular}{|c|c|c|c|c|}
\hline Especie & $\begin{array}{l}\text { Nombre } \\
\text { guaraní }\end{array}$ & Uso & Parte usada & Testigo \\
\hline \multicolumn{5}{|l|}{ Cucurbitaceae } \\
\hline $\begin{array}{l}\text { Lagenaria siceraria (Wol.) } \\
\text { Standl. }\end{array}$ & y'akua & $\begin{array}{l}\text { Recipiente que se cuelga al techo, para } \\
\text { conservar grasas, semillas, ceras, medicina y } \\
\text { miel }\end{array}$ & Frutos & K $564(G)$ \\
\hline \multicolumn{5}{|l|}{ Erythroxylaceae } \\
\hline $\begin{array}{l}\text { Erythroxylum deciduum A. } \\
\text { St.-Hil. }\end{array}$ & yvyra piriri & Horcones centrales y laterales para viviendas & Troncos & T $6754(G)$ \\
\hline \multicolumn{5}{|l|}{ Euphorbiaceae } \\
\hline $\begin{array}{l}\text { Actinostemon concolor } \\
\text { (Spreng.) Müll. Arg. }\end{array}$ & yvyra ũ & $\begin{array}{l}\text { Horcones laterales para viviendas, paredes de } \\
\text { viviendas. Maza para macerar tallos de takuapí. } \\
\text { Varas usadas como sostén para niños que } \\
\text { aprenden a ponerse erguidos y caminar. }\end{array}$ & $\begin{array}{l}\text { Troncos. } \\
\text { Ramas }\end{array}$ & K 245 (S) \\
\hline Ricinus communis L. & ambay & Cultivado como ornamental en patios & Plantas & K 607 (G) \\
\hline $\begin{array}{l}\text { Sebastiania commersoniana } \\
\text { (Baill.) L.B. Sm. \& B.J. Downs }\end{array}$ & $\begin{array}{l}\text { juu rati } \\
\text { mbuku }\end{array}$ & Maza para aplastar cañas takuapí & Ramas & T $5642(\mathrm{G})$ \\
\hline \multicolumn{5}{|l|}{ Fabaceae } \\
\hline $\begin{array}{l}\text { Apuleia leiocarpa (Vogel) J.F. } \\
\text { Macbr. }\end{array}$ & yvyra perẽ & Horcones centrales y laterales para viviendas & Troncos & K $2586(\mathrm{E})$ \\
\hline Calliandra foliolosa Benth. & $\begin{array}{l}\text { tuka revi } \\
\text { kuara, } \\
\text { yro'ycha ja }\end{array}$ & Mazas para aplastar cañas de takuapi & Troncos & K $2458(\mathrm{E})$ \\
\hline Holocalyx balansae Micheli & yvyra рере̃ & $\begin{array}{l}\text { Las hojas se queman frente a la vivienda para } \\
\text { ahuyentar mosquitos y demonios }\end{array}$ & Ramas & K $2513(\mathrm{E})$ \\
\hline $\begin{array}{l}\text { Myrocarpus frondosus Fr. } \\
\text { Allem. }\end{array}$ & yvyra paje & $\begin{array}{l}\text { Horcones centrales y laterales para viviendas. } \\
\text { Se quema frente a la vivienda para ahuyentar } \\
\text { mosquitos y demonios }\end{array}$ & $\begin{array}{l}\text { Troncos, } \\
\text { ramas }\end{array}$ & T 5459 (G) \\
\hline $\begin{array}{l}\text { Parapiptadenia rigida } \\
\text { (Benth.) Brenen }\end{array}$ & kurupay & $\begin{array}{l}\text { Horcones centrales y laterales para viviendas. } \\
\text { Varas usadas como sostén para niños que } \\
\text { aprenden a ponerse erguidos y caminar. }\end{array}$ & $\begin{array}{l}\text { Troncos. } \\
\text { Ramas }\end{array}$ & K $1849(\mathrm{E})$ \\
\hline $\begin{array}{l}\text { Pelthophorum dubium } \\
\text { (Spreng.) Taubert }\end{array}$ & yvyra pytã & Horcones centrales y laterales para viviendas & Troncos & K $5026(\mathrm{E})$ \\
\hline Senna alata (L.) Roxb. & ypoty & Cultivado como ornamental en patios & Plantas & K 803 (G) \\
\hline $\begin{array}{l}\text { Sesbania punicea (Cav.) } \\
\text { Benth }\end{array}$ & ypoty & Cultivado como ornamental en patios & Plantas & K $1775(\mathrm{E})$ \\
\hline \multicolumn{5}{|l|}{ Lauraceae } \\
\hline Ocotea puberula Nees. & aju'y chĩ & Paredes de viviendas, asientos para viviendas & $\begin{array}{l}\text { Troncos } \\
\text { hendidos }\end{array}$ & K $2822(\mathrm{E})$ \\
\hline Persea americana Mill. & parta & Cultivado para sombra en patios & Plantas & K $2398(E)$ \\
\hline \multicolumn{5}{|l|}{ Malvaceae } \\
\hline $\begin{array}{l}\text { Abelmoschus manihot (L.) } \\
\text { Medik. }\end{array}$ & mbo'y kachĩ & i Cultivado como ornamental en patios & Plantas & K 668 (S) \\
\hline $\begin{array}{l}\text { Bastardiopsis densiflora } \\
\text { (Hook. \& Arn.) Hassl. }\end{array}$ & mandyjurã & Soga para hamacas & $\begin{array}{l}\text { Fibras } \\
\text { liberianas }\end{array}$ & K $1944(G)$ \\
\hline \multicolumn{5}{|l|}{ Meliaceae } \\
\hline $\begin{array}{l}\text { Cabralea canjerana (Vell.) } \\
\text { Mart. }\end{array}$ & $\begin{array}{l}\text { yvyra } \\
\text { ruvicha }\end{array}$ & $\begin{array}{l}\text { Horcones centrales y laterales para viviendas. } \\
\text { Soporte para ollas en fogones }\end{array}$ & $\begin{array}{l}\text { Troncos. } \\
\text { Leño }\end{array}$ & K $1886(S)$ \\
\hline
\end{tabular}


BONPLANDIA 17(1): 65-81. 2008

\begin{tabular}{|c|c|c|c|c|}
\hline Especie & $\begin{array}{l}\text { Nombre } \\
\text { guaraní }\end{array}$ & Uso & Parte usada & Testigo \\
\hline Cedrela fissilis Vell. & yary & $\begin{array}{l}\text { Cercos para templos. Horcones centrales y } \\
\text { laterales para viviendas y templos. Asientos } \\
\text { alargados ó zoomórficos para viviendas y } \\
\text { templos. Bateas para contener agua usada en } \\
\text { ceremonias dentro del templo }\end{array}$ & Troncos & K 2505 (E) \\
\hline Melia azedarach $\mathrm{L}$. & paraícho & $\begin{array}{l}\text { Horcones centrales y laterales para viviendas, } \\
\text { asientos de viviendas. Cultivado para sombra en } \\
\text { los patios }\end{array}$ & Troncos & T $6057(G)$ \\
\hline Trichilia catigua A. Juss. & kachygua & Vigas para viviendas & Troncos & K 3002 (L) \\
\hline Trichilia clauseni C.DC. & $\begin{array}{l}\text { yvyra perẽ } \\
\text { mirĩ, yvyra } \\
\text { chanto }\end{array}$ & $\begin{array}{l}\text { Horcones centrales y laterales para viviendas, } \\
\text { paredes de viviendas }\end{array}$ & Troncos & T $5424(G)$ \\
\hline \multicolumn{5}{|l|}{ Moraceae } \\
\hline Morus alba L. & amora & Cultivado para sombra en los patios & Plantas & K 209 (G) \\
\hline $\begin{array}{l}\text { Sorocea bonplandii (Baill.) } \\
\text { W.C.Burger, Lanj. \& } \\
\text { Wess.Boer }\end{array}$ & ñandyta & Refugio contra el jaguar & $\begin{array}{l}\text { Plantas, } \\
\text { ramas }\end{array}$ & T $4731(G)$ \\
\hline \multicolumn{5}{|l|}{ Myrsinaceae } \\
\hline $\begin{array}{l}\text { Myrsine balansae (Mez) } \\
\text { Otegui }\end{array}$ & apere'a ka'a & Horcones centrales y laterales para viviendas & Troncos & K 3048 (S) \\
\hline \multicolumn{5}{|l|}{ Myrtaceae } \\
\hline $\begin{array}{l}\text { Campomanesia xanthocarpa } \\
\text { (Mart.) Berg. }\end{array}$ & guavira & Cultivado para sombra en patios & Plantas & K 2511 (E) \\
\hline Eugenia pyriformis Cambess. & yvaei & Horcones centrales y laterales para viviendas & Troncos & T $5114(G)$ \\
\hline Eugenia uniflora L. & ñangapiri & Horcones centrales y laterales para viviendas & Troncos & T $5487(G)$ \\
\hline Psidium guajava L. & $\begin{array}{l}\text { arachã } \\
\text { guachu }\end{array}$ & Cultivado para sombra en patios & Plantas & K 2569 (E) \\
\hline \multicolumn{5}{|l|}{ Nictagynaceae } \\
\hline Mirabilis jalapa L. & ypoty & Cultivado en patios como ornamental & Plantas & K 684 (S) \\
\hline \multicolumn{5}{|l|}{ Phytolaccaceae } \\
\hline Petiveria alliacea L. & pipi & $\begin{array}{l}\text { Se quema frente a la vivienda para ahuyentar } \\
\text { mosquitos y demonios }\end{array}$ & Plantas & K 705 (S) \\
\hline \multicolumn{5}{|l|}{ Rhamnaceae } \\
\hline \multicolumn{5}{|l|}{ Rosaceae } \\
\hline Prunus persica (L.) Batsch & rurano & Cultivado para sombra en viviendas & Plantas & K 2139 (S) \\
\hline \multicolumn{5}{|l|}{ Rutaceae } \\
\hline $\begin{array}{l}\text { Balfourodendron riedelianum } \\
\text { (Engler) Engler }\end{array}$ & yvyra nechĩ & $\begin{array}{l}\text { Horcones centrales y laterales para viviendas y } \\
\text { templos }\end{array}$ & Troncos & K 2517 (E) \\
\hline Helietta apiculata Benth. & yvyra ovy & $\begin{array}{l}\text { Cercos para templos. Horcones centrales y } \\
\text { laterales para viviendas y templos }\end{array}$ & Troncos & K 1369 (S) \\
\hline Pilocarpus pennatifolius Lem. & yvyra petái & Vigas para viviendas & Troncos & K 3325 (G) \\
\hline \multicolumn{5}{|l|}{ Sapindaceae } \\
\hline Cupania vernalis Cambess & yvata'y ava & $\begin{array}{l}\text { Horcones centrales y laterales para viviendas, } \\
\text { paredes de viviendas }\end{array}$ & Troncos & K 2529 (E) \\
\hline
\end{tabular}


H. A. Keller, Las plantas usadas por los guaraníes en Misiones

\begin{tabular}{|c|c|c|c|c|}
\hline Especie & $\begin{array}{l}\text { Nombre } \\
\text { guaraní }\end{array}$ & Uso & Parte usada & Testigo \\
\hline $\begin{array}{l}\text { Diatenopterix sorbifolia } \\
\text { Radlk. }\end{array}$ & yvyra porã & Horcones centrales y laterales para viviendas & Troncos & K $2510(\mathrm{E})$ \\
\hline Matayba elaeagnoides Radlk. & $\begin{array}{l}\text { yvata'y } \\
\text { kuña }\end{array}$ & $\begin{array}{l}\text { Horcones centrales y laterales para viviendas, } \\
\text { paredes de viviendas }\end{array}$ & Troncos & K 2412 (E) \\
\hline \multicolumn{5}{|l|}{ Sapotaceae } \\
\hline $\begin{array}{l}\text { Chrysophyllum gonocarpum } \\
\text { (Mart. \& Eichler) Engl. }\end{array}$ & aguai & $\begin{array}{l}\text { Cercos para templos. Horcones centrales y } \\
\text { laterales para viviendas }\end{array}$ & Troncos & K 2507 (E) \\
\hline \multicolumn{5}{|l|}{ Solanaceae } \\
\hline $\begin{array}{l}\text { Brugmansia suaveloens } \\
\text { (Willd.) Berch. \& Presl. }\end{array}$ & ypoty & Cultivado como ornamental en patios & Plantas & K 1336 (S) \\
\hline Brunfelsia pilosa Plowman & $\begin{array}{l}\text { ypoty } \\
\text { jovara }\end{array}$ & Cultivado como ornamental en patios & Plantas & K 3101 (S) \\
\hline Nicotiana tabacum L. & petỹ & $\begin{array}{l}\text { Se quema frente a la vivienda para ahuyentar } \\
\text { mosquitos y demonios }\end{array}$ & Hojas & K 679 (S) \\
\hline \multicolumn{5}{|l|}{ Styracaceae } \\
\hline Styrax leprosus Hook. \& Arn. & ka'ovechĩ & Paredes de viviendas & $\begin{array}{l}\text { Troncos } \\
\text { hendidos }\end{array}$ & K 1367 (S) \\
\hline \multicolumn{5}{|l|}{ Turneraceae } \\
\hline $\begin{array}{l}\text { Turnera occidentalis } \\
\text { (Urb.)Arbo }\end{array}$ & ypoty & Cultivado como ornamental en patios & Plantas & K 1865 (S) \\
\hline \multicolumn{5}{|l|}{ Urticaceae } \\
\hline Urera baccifera Wedd. & pynõ & Soga para hamacas & $\begin{array}{l}\text { Fibras } \\
\text { liberianas }\end{array}$ & K 2958 (L) \\
\hline \multicolumn{5}{|l|}{ Verbenaceae } \\
\hline $\begin{array}{l}\text { Aloysia virgata (Ruiz \& Pav.) } \\
\text { Juss. }\end{array}$ & yvyra rei & Paredes de viviendas & Troncos & K 287 (S) \\
\hline $\begin{array}{l}\text { Vitex megapotamica } \\
\text { (Spreng.) Moldenke }\end{array}$ & taruma & $\begin{array}{l}\text { Horcones centrales y laterales para viviendas, } \\
\text { mazas para aplastar cañas takuapi }\end{array}$ & $\begin{array}{l}\text { Troncos, } \\
\text { ramas }\end{array}$ & T 4649 (G) \\
\hline \multicolumn{5}{|l|}{ MONOCOTYLEDONEAE } \\
\hline \multicolumn{5}{|l|}{ Agavaceae } \\
\hline $\begin{array}{l}\text { Cordyline spectabilis Kunth \& } \\
\text { Bouché }\end{array}$ & yvarã & $\begin{array}{l}\text { Material para cubrir techos de quinchos y } \\
\text { viviendas, paredes de viviendas, material para } \\
\text { cubrir hendijas en paredes. Ataduras de poca } \\
\text { duración, }\end{array}$ & $\begin{array}{l}\text { Ramas } \\
\text { apicales. } \\
\text { Hojas }\end{array}$ & K 1352 (S) \\
\hline \multicolumn{5}{|l|}{ Amarylidaceae } \\
\hline $\begin{array}{l}\text { Hippeastrum glaucescens } \\
\text { (Mart.) Herb. }\end{array}$ & tupã poty & Cultivado como ornamental en patios & Plantas & T 5924 (G) \\
\hline \multicolumn{5}{|l|}{ Araceae } \\
\hline $\begin{array}{l}\text { Philodendron bipinnatifidum } \\
\text { Schott }\end{array}$ & guembe & Ataduras de construcciones, soga para hamacas & $\begin{array}{l}\text { Corteza de } \\
\text { las raíces, } \\
\text { raíces }\end{array}$ & K $1432(\mathrm{M})$ \\
\hline \multicolumn{5}{|l|}{ Arecaceae } \\
\hline $\begin{array}{l}\text { Acrocomia aculeata Lodd. ex } \\
\text { Mart. }\end{array}$ & mbokaja & Ataduras de poca duración & Hojas & K 1676 (E) \\
\hline
\end{tabular}




\begin{tabular}{|c|c|c|c|c|}
\hline Especie & $\begin{array}{l}\text { Nombre } \\
\text { guaraní }\end{array}$ & Uso & Parte usada & Testigo \\
\hline $\begin{array}{l}\text { Arecastrum romanzoffianum } \\
\text { (Cham.) Becc. }\end{array}$ & pindo & $\begin{array}{l}\text { Antiguo refugio. Ataduras de poca duración, } \\
\text { material para cubrir techos de viviendas y } \\
\text { quinchos, colchones cobertores de la cama. } \\
\text { Paredes de viviendas y templos, flejes de } \\
\text { camas. Sogas para hamacas. }\end{array}$ & $\begin{array}{l}\text { Planta. Hojas. } \\
\text { Estípites } \\
\text { hendidos. } \\
\text { Fibras de las } \\
\text { vainas foliares }\end{array}$ & K 3431 (S) \\
\hline Butia yatay (Mart.) Becc. & jatay & Techos de refugios, ataduras de poca duración & Hojas & ----- \\
\hline \multicolumn{5}{|l|}{ Bromeliaceae } \\
\hline Bromelia balansae Mez & karaguata & $\begin{array}{l}\text { Antigua cuerda para ataduras de construcción y } \\
\text { para hamacas }\end{array}$ & $\begin{array}{l}\text { Fibras del } \\
\text { rizoma }\end{array}$ & K 1502 (I) \\
\hline \multicolumn{5}{|l|}{ Cannaceae } \\
\hline Canna indica L. & pariri & Antiguo uso para techos de viviendas & Vástagos & K 3064 (G) \\
\hline Canna paniculata Ruiz \& Pav. & pariri & Antiguo uso para techos de viviendas & Vástagos & K 2794 (S) \\
\hline Canna sp. & $\begin{array}{l}\text { peguao } \\
\text { pytã }\end{array}$ & Cultivado como ornamental en patios & Plantas & K $615(G)$ \\
\hline \multicolumn{5}{|l|}{ Cyperaceae } \\
\hline $\begin{array}{l}\text { Bulbostylis juncoides (Vahl) } \\
\text { Kük. \& Herter }\end{array}$ & $\begin{array}{l}\text { aguara } \\
\text { ruguái mirĩ }\end{array}$ & $\begin{array}{l}\text { Usado para hacer chorizos de barro para } \\
\text { paredes de rancho }\end{array}$ & Plantas & K 145 (G) \\
\hline \multicolumn{5}{|l|}{ Iridaceae } \\
\hline $\begin{array}{l}\text { Belamcanda chinensis } \\
\text { (Rheede) Adans. }\end{array}$ & ypoty & Cultivado como ornamental en patios & Plantas & K 1776 (E) \\
\hline \multicolumn{5}{|l|}{ Musaceae } \\
\hline Musa paradisiaca L. & pakova & Material para cubrir hendijas de paredes & Hojas & K 2127 (G) \\
\hline \multicolumn{5}{|l|}{ Poaceae } \\
\hline Andropogon bicornis L. & $\begin{array}{l}\text { aguara } \\
\text { ruguái }\end{array}$ & $\begin{array}{l}\text { Material para cubrir techos de viviendas y } \\
\text { quinchos, paredes de viviendas, material para } \\
\text { tapar hendijas de paredes }\end{array}$ & Vástagos & K $629(G)$ \\
\hline Arundo donax L. & $\begin{array}{l}\text { takua } \\
\text { morotĩ, } \\
\text { takuaty, } \\
\text { takuachĩ }\end{array}$ & $\begin{array}{l}\text { Material para cubrir techos de viviendas y } \\
\text { quinchos }\end{array}$ & Tallos & K 1042 (E) \\
\hline $\begin{array}{l}\text { Axonopus compressus (Sw.) P. } \\
\text { Beauv. }\end{array}$ & kapi'i pe & Encespedado de patios & Plantas & K $589(G)$ \\
\hline Bambusoideae: Gén indet. & takua ovy & $\begin{array}{l}\text { Material para cubrir techos de viviendas y } \\
\text { quinchos }\end{array}$ & Tallos & ----- \\
\hline Chloris polydactyla (L.) Sw. & kapi'i y & $\begin{array}{l}\text { Material para cubrir techos de viviendas y } \\
\text { quinchos }\end{array}$ & Vástagos & Co $7977(\mathrm{E})$ \\
\hline Cynodon dactylon (L.) Pers. & $\begin{array}{l}\text { kapi'i poñy, } \\
\text { kapi'i pe }\end{array}$ & $\begin{array}{l}\text { Se pone la planta cubriendo el piso de los } \\
\text { ranchos, para refrescar y como cama }\end{array}$ & Plantas & T 6493 (G) \\
\hline Erianthus trinii (Hack.) Hack. & $\begin{array}{l}\text { kapi'i } \\
\text { guazu, } \\
\text { kapi'i } \\
\text { pororo }\end{array}$ & $\begin{array}{l}\text { Material para cubrir techos de viviendas y } \\
\text { quinchos }\end{array}$ & Vástagos & K 587 (G) \\
\hline Gén. Indet. & pachorí & $\begin{array}{l}\text { Material para cubrir techos de viviendas y } \\
\text { quinchos }\end{array}$ & Hojas & K 1909 (E) \\
\hline Guadua angustifolia Kunth & takuaruchu & Bastidor del techo & Tallos & K 1681 (E) \\
\hline
\end{tabular}




\begin{tabular}{|c|c|c|c|c|}
\hline Especie & $\begin{array}{l}\text { Nombre } \\
\text { guaraní }\end{array}$ & Uso & Parte usada & Testigo \\
\hline Guadua trinii (Nees) Rupretch & pekuru & $\begin{array}{l}\text { Bastidor del techo. Material para cubrir techos } \\
\text { de viviendas y quinchos, paredes de viviendas }\end{array}$ & Tallos & K 1375 (I) \\
\hline Merostachys clausseni Munro & $\begin{array}{l}\text { takuapi, } \\
\text { ñanderopy } \\
\text { ova }\end{array}$ & $\begin{array}{l}\text { Ataduras de construcción, bastidor del techo, } \\
\text { material para cubrir techos de templos, } \\
\text { viviendas y quinchos, paredes de viviendas, } \\
\text { bastidor para el adobe que cubre paredes de } \\
\text { viviendas y templos, flejes de repisas, varas } \\
\text { para colgar semillas y materiales a secar sobre } \\
\text { el fogón, flejes de camas. Recipientes para } \\
\text { conservar medicinas, miel, grasas y ceras }\end{array}$ & $\begin{array}{l}\text { Tallos, hojas. } \\
\text { Entrenudos }\end{array}$ & K 2828 (S) \\
\hline Oryza rufipogon Griff. & arõ & Material para cubrir techos de quinchos & Vástagos & K $670(S)$ \\
\hline Oryza sativa $\mathrm{L}$. & arõ & Material para cubrir techos de quinchos & Vástagos & K $3408(G)$ \\
\hline Panicum prionitis Nees & $\begin{array}{l}\text { kapi'y } \\
\text { pororo }\end{array}$ & $\begin{array}{l}\text { Material para cubrir techos de viviendas y } \\
\text { quinchos }\end{array}$ & Vástagos & ----- \\
\hline $\begin{array}{l}\text { Paspalum quarinii Morrone \& } \\
\text { Zuloaga }\end{array}$ & $\begin{array}{l}\text { kapi'y, } \\
\text { kapi'y } \\
\text { guazu }\end{array}$ & $\begin{array}{l}\text { Material para cubrir techos de viviendas y } \\
\text { quinchos }\end{array}$ & Vástagos & $\begin{array}{l}\text { MC } 5929 \\
\text { (C) }\end{array}$ \\
\hline Pennisetum purpureum L. & kapi'i yvate & Material para cubrir techos viviendas y quinchos & Tallos & K 1331 (S) \\
\hline Saccharum villosum Steud. & $\begin{array}{l}\text { kapi'i } \\
\text { guazu, } \\
\text { kapi'i } \\
\text { pororo }\end{array}$ & $\begin{array}{l}\text { Material para cubrir techos de viviendas y } \\
\text { quinchos }\end{array}$ & Vástagos & ----- \\
\hline $\begin{array}{l}\text { Schizachyrium microstachyum } \\
\text { (Desv.) Roseng., B.R. Arrill. \& } \\
\text { Izag. }\end{array}$ & kapi'i pytã & $\begin{array}{l}\text { Material para cubrir techos de viviendas y } \\
\text { quinchos, paredes de viviendas, material para } \\
\text { cubrir hendijas de paredes }\end{array}$ & Vástagos & K 712 (S) \\
\hline Zea mays L. & avachĩ & $\begin{array}{l}\text { Soga para hamacas. Material para cubrir } \\
\text { hendijas }\end{array}$ & $\begin{array}{l}\text { Brácteas de } \\
\text { la espiga. } \\
\text { Vástagos }\end{array}$ & K 671 (S) \\
\hline
\end{tabular}


BONPLANDIA 17(1): 65-81. 2008 